\title{
Role of Yttrium Substitution in the Atomic Cluster Evolution and Corrosion Behaviour of Al-Ni-Gd Metallic Glasses
}

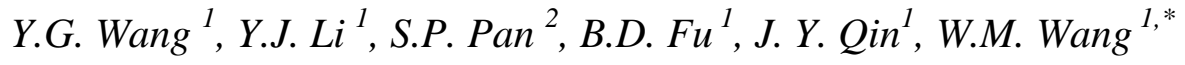 \\ ${ }^{1}$ Key Laboratory for Liquid-Solid Structural Evolution and Processing of Materials, Ministry of \\ Education, Shandong University, Jinan 250061, China \\ ${ }^{2}$ Department of Material Science and Engineering, Taiyuan University of Technology, Taiyuan \\ 030024, China \\ *E-mail: weiminw@sdu.edu.cn
}

doi: $10.20964 / 110429$

Received: 30 January 2016 / Accepted: 2 March 2016 / Published: 1 April 2016

\begin{abstract}
Atomic cluster evolution and corrosion behaviour of $\mathrm{Al}_{84} \mathrm{Ni}_{10} \mathrm{Gd}_{6-x} \mathrm{Y}_{x}(x=0,2,4$ and 6) metallic glasses were investigated using experimental methods and ab initio molecular dynamic simulations. The shoulder peak area in x-ray diffraction patterns, enthalpy of second and third crystallization and population of $<0360>\mathrm{Ni}$-centered clusters increase with increasing yttrium content, but the onset temperature and enthalpy of first crystallization decrease simultaneously. Yttrium substitution and annealing treatment can aggravate metastable pitting and induce a thicker alumina film during polarization, which can be explained by the segregation of Ni-centered clusters and ordering of Al-rich clusters.
\end{abstract}

Keywords: Metallic glass; Al alloy; Corrosion; Pitting.

\section{FULL TEXT}

(C) 2016 The Authors. Published by ESG (www.electrochemsci.org). This article is an open access article distributed under the terms and conditions of the Creative Commons Attribution license (http://creativecommons.org/licenses/by/4.0/). 